\title{
CONSTRUÇÕES IDENTITÁRIAS BISSEXUAIS E MATRIZES HETERO E HOMONORMATIVAS
}

\author{
Cosme Rezende Laurindo ${ }^{1}$
}

Resumo: Este estudo surge a partir de um processo de identificação próprio, bem como de adoecimento e interesse particular em compreender de que maneira vem se discutindo a bissexualidade enquanto identidade legítima, os atravessamentos que isto traz e como este debate se insere na discussão ainda hegemônica de leitura de mundo em matrizes duas: hetero- e homonormativas. Trata-se de um ensaio teórico, a partir de duas dissertações de mestrado, tendo-se como referenciais teóricos os olhares da Teoria Queer e das Epistemologias Bissexuais. A forma como a bissexualidade, enquanto identidade, é vista atualmente, impacta em sua construção, de maneira que os processos de invisibilização e de marginalização retomam concepções e paradigmas não atuais, atuando enquanto fatores que propiciam o apagamento desta sexualidade dentro da comunidade LGBTQI+ e reforçando relações de poder excludentes a partir das matrizes hegemônicas: heterno- e homonormativas.

Palavras-chave: Construção Identitária; Bissexualidade; Sexualidades.

\section{Introdução}

Senti-me provocado a me debruçar sobre um tema que me é caro, que é a compreensão da bissexualidade enquanto identidade legítima, os atravessamentos que isto traz e de que forma este debate se insere na discussão ainda hegemônica de leitura de mundo em matrizes duas: hetero- e homonormativas. Este trabalho surge a partir de um

\footnotetext{
${ }^{1}$ Bacharel em Enfermagem pela Universidade Federal de Juiz de Fora (UFJF) (2017). Especialista em Saúde Mental - Modalidade Residência Multiprofissional pela UFJF (2020). Aperfeiçoando em Atenção à Saúde no Sistema Prisional pela Escola Nacional de Saúde Pública (ENSP/ Fiocruz - RJ). Mestrando no Programa de Pós-Graduação em Saúde Coletiva (PPGSC) da UFJF. Pesquisador do GEDIS: Grupo de Estudos e Pesquisas em Sexualidade, Gênero, Diversidade e Saúde: Políticas e Direitos (UFJF); Grupo de Estudos sobre a Doença Pulmonar Obstrutiva Crônica - GEDPOC (UNIPAC-JF); e Núcleo de Estudos em Infecções e Complicações relacionadas à Assistência à Saúde (NEICAS) (UFJF). Email: cosmelaurindo@outlook.com
}

Vol. 03, N. 10, Abr. - Jun., 2020 - http://periodicoscientificos.ufmt.br/ojs/index.php/rebeh/index 


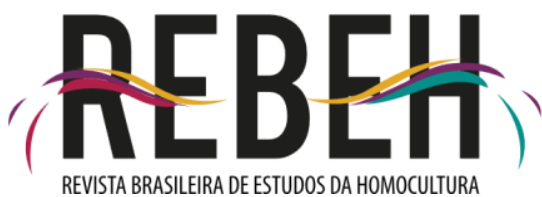

processo de identificação próprio, bem como de adoecimento e interesse pessoal em entender de que maneira vem se discutindo tal questão, vide dificuldades de acesso a estes debates ao longo de minha formação e nos espaços de militância os quais ocupei.

Identifico-me enquanto homem, negro, bissexual, e, por vezes, deparo-me com uma leitura distinta da sociedade frente à minha existência e com questionamentos diversos pautados a partir do que está construído no imaginário social quanto ao que é legítimo de ser performado e expresso enquanto sexualidade. Desta forma, foram vários os espaços em que houve necessidade de reafirmação de minha identidade frente a contestações reducionistas quanto às sexualidades. Estas, dadas a partir de mera avaliação quantitativa de relacionamentos anteriores, desconsiderando aquilo que não é concreto, que diz do campo do afeto e de entendimento subjetivo de mundo, com presença de julgamento tanto por pessoas heterossexuais, quanto por pessoas não heterossexuais.

Metodologicamente procedo a um ensaio teórico, justificado por sua natureza reflexiva e interpretativa frente à realidade (ADORNO, 1986), com riqueza por oportunizar a originalidade, característica elementar desta modalidade de escrita (MENEGHETTI, 2011). A organização parte desta introdução, na qual consta a conceituação referente ao escopo de discussão, e capítulos de reflexão e crítica (SEVERINO, 1986).

A crítica foi tecida a partir de duas dissertações de mestrado. A primeira, intitulada "“Não é uma fase": construções identitárias em narrativas de ativistas LGBT que se identificam como bissexuais”, defendida por Elizabeth Sara Lewis, em 2012, ao programa de Pós-Graduação em Letras do Departamento de Letras do Centro de Teologia e Ciências Humanas da Pontifícia Universidade Católica do Rio de Janeiro (PUC-Rio). E a segunda, intitulada "Visíveis e Invisíveis: práticas e identidade bissexual", defendida por Camila Dias Cavalcanti, em 2007, ao programa de Pós-graduação em Sociologia do Centro de Ciências Humanas e Filosofia da Universidade Federal de Pernambuco. As dissertações foram escolhidas por compartilharem mesma perspectiva teórica e estarem alinhadas com as concepções a serem aqui defendidas. Limitei a dois materiais visando discussão sucinta e objetiva, tendo como referenciais teóricos os olhares da Teoria Queer e das Epistemologias Bissexuais. 


\section{员드댄}

Os estudos foram analisados a partir da análise textual discursiva, seguindo o que é proposto por Moraes (2003), perpassando as etapas de: desmontagem dos textos, na qual há leitura minuciosa e análise dos materiais, dividindo-os em unidades e enunciados referentes ao escopo do estudo; categorização, etapa na qual cada unidade e enunciado foram organizados de acordo com a relação existente entre eles, constituindo conjuntos de conhecimento; e captação do novo emergente, etapa na qual debrucei sobre os conjuntos levantados previamente, tecendo uma nova concepção a partir das críticas e olhar pessoal.

Compreendo a dificuldade e a limitação de se palpar um objeto que traz consigo algo escorregadio e invisível, atestando que o interesse deste ensaio não é reforçar estereótipos ou preconceitos, mas sim entender a bissexualidade a partir de concepções ainda não acessadas ao longo de minha formação profissional.

\section{Posicionamento teórico: identidades e sexualidades}

Cabe aqui explicitar o meu posicionamento teórico frente a compreensão de identidade e sexualidades que vai de encontro ao que defende Lewis (2012, p.16), quando discute partir de duas ideias inter-relacionadas:

[...] primeiro a visão da teoria Queer (BUTLER, 1990; 1993) de que as identidades não são expressões de alguma essência fixa interna, mas são dinâmicas e construídas discursivo-perfomativamente na linguagem e nas interações e, segundo, a perspectiva de que as categorias da sexualidade que usamos (heterossexualidade, homossexualidade, bissexualidade, etc.) não são fatos naturais, mas são sócio-histórico-culturalmente construídas.

Visando destacar a partir de qual ótica analiso a construção da identidade bissexual e seu potencial político, parto do entendimento de que hegemonicamente estamos envoltos por sistemas de restrições sociais, quer seja a partir de uma matriz heteronormativa, quer seja, dentro do movimento LGBTQI+, uma matriz homonormativa.

A matriz heteronormativa, é aquela que preconiza o alinhamento entre sexo e gênero, de tal forma que a expressão do desejo sexual e afetivo se dê por pessoas de sexo/gênero "oposto", marginalizando pessoas que não se identifiquem desta forma. Já a 


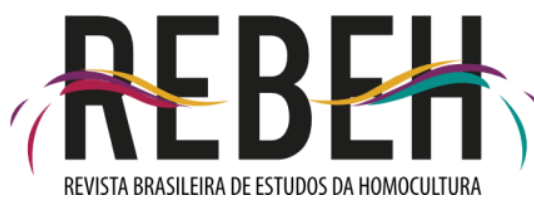

matriz homonormativa, apresenta-se enquanto sistema de restrição dentro da própria comunidade LGBTQI+, com exigência da expressão do desejo sexual e afetividade por pessoas do "mesmo" sexo/gênero, marginalizando aquelas que não se enquadrarem neste perfil (BUTLER, 1990, 1993).

Neste contexto, a bissexualidade manifesta-se enquanto objeto a ser marginalizado por ambos os sistemas sociais restringentes, acarretando negação de sua legitimidade, ao que, se reconhecermos potencial para desestruturação de ambos os sistemas hegemônicos, teria seu potencial pouco explorado, sendo então necessário compreender não só o que "é" ser bissexual, mas sim, o que se pode fazer a partir dessa existência.

\section{Construção sócio-histórica da(s) bissexualidade(s)}

Para que se possa discutir a respeito das implicações atuais da defesa pela legitimidade da existência da bissexualidade, bem como compreender os atravessamentos a partir dos sistemas sociais restringentes hegemônicos, faz-se importante levantar, de forma sucinta, a etimologia da palavra "bissexual", bem como descrever brevemente a história das práticas bissexuais.

Pode-se dividir o uso da palavra "bissexual" em três grandes momentos, influenciados pelo contexto histórico e político de quando foram cunhados. O primeiro grande momento sendo entre o séc. XVII e início do séc. XX, com o uso da palavra para descrever pessoas com corpos de atributos biológicos e anatômicos considerados femininos e masculinos. O segundo, a partir do campo da psicanálise, do séc. XIX até o séc. XX, como referência para pessoas com uma suposta combinação de masculinidade e feminilidade psicológica, em vez de anatômica, com dicotomia de compreensão de um sujeito que em algum momento viria a se diferenciar em hetero- ou homossexual. E o terceiro, em que a palavra passa a indicar desejo sexual que "combina" ou "une" a heterossexualidade e a homossexualidade, sendo ainda presente enquanto forma de leitura do termo, com ênfase a partir dos anos 70 (LEWIS, 2012).

A partir do levantamento destes três momentos históricos, pode-se perceber a relação ainda socializada entre a identidade bissexual enquanto um intermédio frente às 


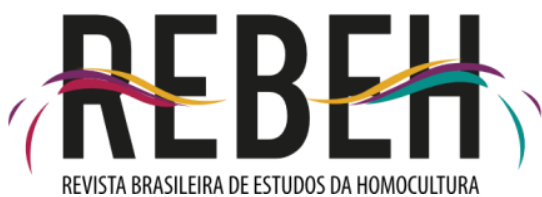

identidades hegemônicas hetero- e homossexual. E, ainda, identificar a existência de processos de silenciamento identitário, pela negação de uma sexualidade pela via da compreensão relativamente recente de que nada mais seria que uma materialização combinada de duas sexualidades, com ainda possibilidade de domínio de uma sobre a outra, abrindo precedente para o entendimento não de uma identidade, mas sim de práticas performadas pelas duas outras hegemônicas.

Assim, passo a defender a leitura de distinção entre "identidade bissexual", categoria identitária assumida por certas pessoas e o sentimento de identificação construído e performado, e "práticas bissexuais", prática de relações sexuais com pessoas de "ambos" os "sexos" (entendendo, neste quesito, "sexo" enquanto homem e mulher) (LEWIS, 2012). Leitura esta reforçada pela constatação história de práticas, neste contexto, tidas enquanto bissexuais, que Lewis (2012) a partir de Mengel (2009), sintetiza em quatro marcos importantes:

A) A pederastia na Grécia antiga, em que as relações bissexuais detinham objetivos voltados à: 1) reprodução, quando entre "sexos" opostos; e 2) educação como cidadão e fortalecimento das forças armadas, quando entre mesmo "sexo" (no caso, entre homens), em que apesar de identificar certa preferência, isto não implicava em uma leitura de identidade, sendo imprescindível à relação a diferença de faixa etária e de posição social;

B) O shudo do Japão Antigo, com semelhança quanto a compreensão dos gregos da necessidade das práticas bissexuais, mas com a relação limitada à formação do aprendiz, além de não se estender ao campo de batalha como estratégia militar, ao que, sustentado pela religião como ato divino de passagem de ensinamentos, superava a leitura moral do ato em si;

C) As relações de dominação e submissão na Roma antiga, em que as relações sexuais eram aceitas entre quaisquer parceiros(as), desde que houvesse uma ordem simbólica de dominação, na qual a penetração era proferida do homem para mulher, do mestre para o escravo, do homem romano para homens estrangeiros, sendo então definida a partir da pessoa de maior posição social sobre a de menor;

Vol. 03, N. 10, Abr. - Jun., 2020 - http://periodicoscientificos.ufmt.br/ojs/index.php/rebeh/index 


\section{REBE员}

D) As práticas bissexuais em tribos e povos indígenas, em que as relações monossexuais eram incomuns em religiões politeístas e não heterocentristas, inclusive desestimuladas por compreensão de xamãs de que limitariam o entendimento daqueles que não pautassem suas vivências neste tipo de relação.

Esses quatro momentos trazem subsídios para entender a mudança da concepção quanto às práticas bissexuais. Que detinham um lugar na sociedade, evidentemente não enquanto construção de identidades distintas, mas que de alguma maneira foram cada vez mais suprimidas e invisibilizadas, tornando a performance dos atos (atualmente já dentro de uma construção de identidade) repudiados frente às duas matrizes hegemônicas, com processos de exclusão pelo meio heterossexual e pelo meio LGBTQI+, frente à matriz homonormativa.

Para além disso, oferta também possibilidade de compreensão frente a certa centralidade na performance de papeis rígidos no ato sexual, com supervalorização daquele que penetra frente aquele que é penetrado, restringindo a manifestação sexual de identidades não heterossexuais à uma prática com leitura evidentemente heteronomartiva, trazendo assim o quão limitada ainda é a (des)construção das relações sexuais, e, por conseguinte, das identidades, visto a força de sistemas de restrição hegemônicos.

\section{Bissexualidade na modernidade}

A identidade sexual vem por muito tempo sendo vista como um conceito unitário, do qual elementos e outras possibilidades são excluídas e negadas aos sujeitos no processo de construção de suas identidades sociais (POLICARPO, 2016), tal como pode-se verificar a partir do levantamento histórico prévio. Isto faz com que de forma distinta aos casos isolados que sofriam estigmatização na época de prática bissexuais (quando não condizentes com o que socialmente era construído enquanto possibilidade de performance destas práticas), ocorra atualmente estigmatização de qualquer prática, sentimento ou sujeito considerado não heteronormativo.

Lewis (2012) a partir de Coleman ([1994]; [1998]; 1999), traz os paradigmas modernos para a compreensão da bissexualidade, de forma a avançar nas discussões 


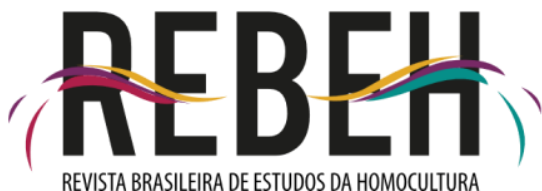

iniciadas a partir da contextualização história dos sentidos atribuídos à identidade e às práticas. São estabelecidos três paradigmas (COLEMAN, [1994]; [1998]; 1999, apud LEWIS, 2012, p.36-37):

No primeiro, são reconhecidas distinções da "orientação sexual" dicotômica (heterossexualidade/homossexualidade) ou tricotômica (heterossexualidadebissexualidade-homossexualidade); nessa visão, há duas ou três "condições" distintas da sexualidade. Esse paradigma dominou o século XX. [...] No segundo paradigma, em vez de reconhecer só duas ou três categorias da sexualidade humana, ela é concebida como um contínuo, porém, não vai além da noção que os genitais do objeto de desejo determinam a "orientação sexual" do sujeito desejante. Essa visão [...] começou em meados do século XX e foi modelo dominante até o século XXI. No terceiro paradigma, é questionada a pressuposição básica que a sexualidade seja determinada pelos genitais do objeto do desejo. Essa visão rompe com o determinismo biológico, reconhecendo que uma pessoa pode estar atraída a outra por razões que vão além do sexo biológico, como a identidade de gênero e o papel sexual.

A concepção mais atualmente socializada traz, de maneira oposta às anteriores, um movimento de desconstrução de identidade bissexual, bem como de todas as identidades, deslocando o reconhecimento identitário de objeto de desejo quantificáveis ou materiais. E, neste sentido, por si só legitima a existência, uma vez que procura desconstruí-la. Apesar disto, esta concepção ainda é passível de aprofundamento analítico, visando entendimento de sexualidade como desejo para além dos fatores biológicos e perfomativo-identitários.

\section{Atravessamentos a partir da percepção de não reconhecimento e não legitimação}

\section{da bissexualidade}

Embora a compreensão de que o objeto de estigma sejam as identidades não heteronormativas, quando se considerado o que vem sendo construído socialmente, percebe-se que para além dessa matriz hegemônica, há ainda um outro lugar de exclusão ocupado pelas pessoas que se identificam enquanto bissexuais dentro da comunidade LGBTQI+, a partir do não enquadramento das categorias binárias normativas da sexualidade (GÓMEZ; ARENAS, 2019). Entendo que apesar da homossexualidade localizar-se enquanto sexualidade marginalizada frente a dicotomia de análise 


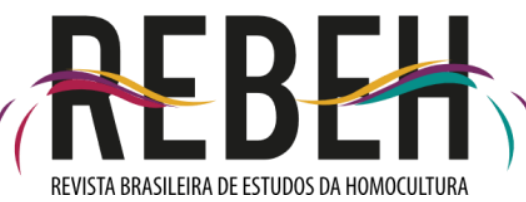

hetero/homo, possui um lugar consolidado e capaz de reproduzir processos de estigmatização (LEWIS, 2012).

Garber (1999) traz que o desconforto com aquilo que de alguma maneira não cabe na leitura do binarismo, para além do medo da ambiguidade de sentido materializado pelas leituras sociais de uma sexualidade intermediária, provém de um medo de perda de coesão dentro do próprio movimento LGBTQI+. Visto surgimento do movimento pautado no compartilhamento de experiências homossexuais e, por conseguinte, rejeição total dos modelos heteronormativos.

Nesta perspectiva, há quem entenda a bissexualidade enquanto objeto não com potencial de desconstrução do modelo dicotômico vigente, mas sim enquanto reforçador deste, por ocupar lugares que seriam de alguma maneira maleáveis, apesar deste discurso trazer consigo compreensão ultrapassada quanto ao que seja a construção da identidade bissexual, retomando o que neste ensaio foram o primeiro e o segundo paradigmas modernos.

Esta reflexão demonstra que ainda está introjetada em nossa cultura a representação majoritária da sexualidade organizada em dois polos bem marcados, a heterossexualidade e a homossexualidade, cada polo correspondendo a identidades bem definidas, quais sejam, os heterossexuais e os homossexuais (CAVALCANTI, 2007). E, desta forma, indivíduos bissexuais passam muitas vezes despercebidos, invisíveis numa representação e significação onde se faz proibido discordar de uma lógica binária e polarizada (SANTOS et al., 2018).

Ainda assim, o mesmo processo de marginalização já sinaliza potencial de rompimento com o que está de hegemônico, bem como demonstra que é possível, através do incômodo da ordem social atual, oxigenar as discussões e avançar no debate frente à multiplicidade de sexualidades.

Neste contexto, pensar a bissexualidade é problematizar a naturalidade que durante muito tempo segmentou os sujeitos em categorias e classificações como forma de controlar a sua sexualidade, reprodução e outras maneiras de controle social, a partir de leituras rígidas quanto a papeis desempenhados socialmente, questionando a forma de tratamento da sexualidade em si enquanto única e imutável (CAVALCANTI, 2007). 


\section{REBE员}

Cavalcanti (2007) traz ainda que ao questionar as certezas rígidas, amplia-se a discussão das sexualidades para formas de identificação mais flexíveis ou performáticas, tal como nos apresenta Butler (1990) em seu debate, possibilitando problematização frente ao que era tido como normal ou natural, a partir da legitimação de formas de vivências que, até então, pareciam impossíveis ou absurdas.

Essa rigidez presente atualmente provém de um sistema que pauta a "heterossexualidade compulsória", como traz Lewis (2012), uma vez que estejamos imersos em normas sociais que produzem a matriz heteronormativa, fortalecem o determinismo biológico enquanto método de análise de gênero e perpetuam, de alguma maneira, a matriz homonormativa na comunidade de LGBTQI+, enquanto estratégia equívoca de persistência.

A bissexualidade, neste contexto, fazendo-se valer da leitura social daquilo que está no intermédio, pode atuar enquanto identidade com potencial para desestabilização do sistema, sendo uma das materializações de agência frente a um sistema impossível de mudança abrupta, visto que esta mudança não seria inteligível para aqueles que estão dentro do sistema, isto é, não teria efeito de mudança permanente, apenas de rompimento pontual e que inclusive geraria repúdio pela não compreensão (LOURO, 2004, apud CAVALCANTI, 2007).

Detendo este potencial, a bissexualidade se torna objeto de silenciamento, uma vez que a manutenção da ordem esteja posta enquanto objetivo da sociedade moderna, ordem esta que, de certa maneira, se introjeta na comunidade LGBTQI+, distanciando o reconhecimento e a legitimação da bissexualidade enquanto identidade, reforçando a marginalização destes sujeitos e impactando negativamente na construção formal desta identidade.

\section{Considerações Finais}

A forma como a bissexualidade, enquanto identidade, é vista atualmente, impacta em sua construção, de maneira que os processos de invisibilização e de marginalização retomam concepções e paradigmas não atuais, atuando enquanto fatores que propiciam o 
apagamento desta sexualidade dentro do meio LGBTQI+ e, a partir deste, a desmobilização política dos sujeitos e a existência pouco evidente de ativistas pela causa.

A pesar deste processo, entendo a legitimação e reconhecimento da bissexualidade enquanto identidade, não pelo que se "é", mas pelo que se pode fazer a partir do que se "é”. Enquanto caminho de superação frente a polaridade que conduz a compreensão frente a orientação sexual e identificação, que ainda nos aprisiona a uma representação binária, reflexo de relações de poder excludentes a partir das matrizes hegemônicas hetero- e homonormativas.

Reconheço que apesar de haver mais produções existentes do que é feito parecer que existem, a bissexualidade e suas práticas carregam ainda mais indagações do que respostas, sendo necessário pensar nas relações que envolvem gênero, identidade, faixa etária, posição social e todos os estigmas que marcam os indivíduos por não corresponderem à norma heterossexual, que atende à uma matriz hegemônica construída por um sistema social de normas vigentes.

\section{Referências}

ADORNO, T. W.. O ensaio como forma. In: COHN, G. (Org.). Sociologia: Adorno. São Paulo: Ática, 1986. p. 167-187.

BUTLER, J. Bodies That Matter: On the Discursive Limits of "Sex". Routledge: Nova York e Londres, 1993.

BUTLER, J. Gender Trouble: Feminism and the Subversion os Identity. Routledge: Nova Iorque e Londres, 1990.

CAVALCANTI, C. D.. Visíveis e Invisíveis: práticas e identidade bissexual. Orientador: Prof. Remo Mutzenberg. 2007. 112 f. Dissertação (Mestrado) - Curso de Pósgraduação em Sociologia, Centro de Ciências Humanas e Filosofia, Universidade Federal de Pernambuco, Recife, 2007.

GARBER, M. Extracts from Vice Versa: bisexuality and the eroticism of everyday life (1995). In: STORR, M. (org.). Bisexuality: a critical reader. Londres e Nova Iorque: Routledge, 1999. Cap. 14. p. 138-143.

GÓMEZ, J. P. P.; ARENAS, Y.. Development of Bisexual Identity. Ciência \& Saúde Coletiva, [Internet], v. 24, n. 5, p. 1669-1678, maio 2019.

LEWIS, E. S.. "Não é uma fase": construções identitárias em narrativas de ativistas LGBT que se identificam como bissexuais. Orientadora: Profa. Liliana Cabral Bastos. 2012. 267 f. Dissertação (Mestrado) - Curso de Pós-graduação em Letras, Centro de

Vol. 03, N. 10, Abr. - Jun., 2020 - http://periodicoscientificos.ufmt.br/ojs/index.php/rebeh/index 
Teologia e Ciências Humanas, Pontifícia Universidade Católica do Rio de Janeiro, Rio de Janeiro, 2012.

MENEGHETTI, F. K.. O que é um Ensaio-Teórico? RAC, Curitiba, v. 15, n. 2, p.320332, mar./abr. 2011.

MORAES, R.. Uma tempestade de luz: a compreensão possibilitada pela análise textual | 58 discursiva. Ciência \& Educação, [on-line], v. 9, n. 2, p.191-211, 2003.

POLICARPO, V. M. N. M.. Para lá da heteronorma: subjetivação e construção da identidade sexual. Revista Estudos Feministas, [Internet], v. 24, n. 2, p. 541-562, ago. 2016.

SANTOS, C. G. C. P. et al. Da invisibilidade ao reconhecimento: experiência de roda de conversa e validação da bissexualidade em São Paulo. BIS, [Internet], v. 19, n. 2, p. 16691678, dez 2018.

SEVERINO, A. J.. Metodologia do trabalho científico. 14. ed. São Paulo: Cortez, 1986.

\title{
BISEXUAL IDENTITY CONSTRUCTS AND HETERO AND HOMONORMATIVE MATRICES
}

\begin{abstract}
: this study arises from a process of self-identification, as well as from illness and particular interest in understanding how bisexuality has been discussed as a legitimate identity, the crossings that this brings and how this debate is inserted in the still hegemonic discussion of reading world in two matrices: hetero- and homonormative. This is a theoretical essay, based on two master's dissertations, taking as a theoretical framework the views of Queer Theory and Bisexual Epistemologies. The way bisexuality, as an identity, is currently seen, has an impact on its construction, so that the processes of invisibility and marginalization resume non-current concepts and paradigms, acting as factors that favor the erasure of this sexuality within the LGBTQI + community and reinforcing excluding power relations based on hegemonic matrices: heterogeneous and homonormative.
\end{abstract}

Keywords: Identity Construction. Bisexuality. Sexualities.

Recebido: 30/07/2020

Aceito: 09/09/2020 